\title{
Determination of Fatigue Crack Growth Trajectory and Residual Life under Mixed Modes
}

\author{
Marija Blažić ${ }^{1, *}$ - Stevan Maksimović1 - Zlatko Petrović 3 - Ivana Vasović2 - Dragana Turnić $^{4}$ \\ ${ }^{1}$ Military Technical Institute, Serbia \\ 2 Institute Goša, Serbia \\ 3 University of Belgrade, Faculty of Mechanical Engineering, Serbia \\ ${ }_{4}^{4}$ University of Belgrade, Faculty of Civil Engineering and Architecture, Serbia
}

\begin{abstract}
This paper considers the determination of the crack growth trajectory and residual life for the two-dimensional structural elements under mixed modes. To study crack growth behaviour, a specimen with two holes and a crack between them is considered. This crack is defined as achieving a mixed-mode I/II crack growth trajectory. To produce a crack growth trajectory under cyclic loads with an initial crack between the two holes, MTS servo-hydraulic system is used. Crack growth trajectory is defined using numerical simulations via finite elements. The results of the numerical simulations by finite elements are compared with experimental results. Residual life along the 'curve' mixed-mode crack growth trajectory is determined numerically and experimentally. The crack growth trajectory obtained via the presented numerical simulation and residual life are compared with own experimental results.
\end{abstract}

Keywords: fatigue crack growth, mixed modes, residual life estimation, finite element simulation

\section{INTRODUCTION}

The design considerations of aircraft structures based on damage tolerance approach often require the prediction of mixed-mode fatigue crack growth. In this approach, the propagation path of a crack in a part is an essential aspect for the fatigue life simulation using the methodology of fracture mechanics. However, most of the existing approaches are limited to the mode- $I$ fatigue crack growth cases (e.g. [1] to [4]). These approaches are generally based on correlations between the fatigue crack growth rate $(d a / d N)$ and the range of the mode- $I$ stress intensity factor $\left(\Delta K_{I}\right)$. The commonly used fatigue crack growth rate equation is [5]:

$$
\frac{d a}{d N}=C(\Delta K)^{n}
$$

involving the experimentally determined constants $C$ and $n$ may not be adequate, because they are restricted to cracks running in a straight line. In the damage tolerance approach, the propagation path of a crack in a part is an essential aspect for fatigue life simulation using fracture mechanics methodology. For these cases, the cracks do not propagate in the direction normal to the applied load; these models need the stress intensity factor history along the crack path.

Interesting attempts to predict the angle of crack propagation, as well as the fatigue crack growth rate for mixed-mode cracks, are divided into two categories. The first incorporates the methodologies that consider the stress or the strain as the fatigue crack growth driving force, e.g. the maximum tangential stress (MTS) criterion [6] and [7], the tangential stress factor and tangential strain factor [8], the maximum tangential strain criterion [9], etc. The second category contains the methodologies that recognize the material strain energy density as the fatigue crack growth driving force, e.g. the minimum strain energy density $(S)$ criterion [10] to [12], the dilatational strain energy density $(T)$ criterion [13] and [14], etc.

In previously mentioned works, the distribution of the total or the dilatational elastic strain energy density around the crack tip is evaluated along a circular core or the elastic-plastic boundary region before the crack extension. It is postulated that the mixed-mode fatigue crack propagates along a direction defined by a minimum for the total strain energy density [10] to [12] or by a maximum for the dilatational component of the strain energy density [13] and [14]. However, these postulations are mostly based on hypothetical approaches [15]. The accuracy of their predictions depends on several parameters, including the material ductility [13], load mixities [15], etc. In this paper, the development of a method supported by a better physical basis is attempted. To this scope, the tendency of the elastic stress field to minimize the accumulated elastic strain energy (e.g. [9] to [15]) (not the energy density) is taken into account. The proposed methodology differs from the previous methodologies in the following points: a) The factor controlling the mixed-mode crack propagation is the accumulated energy, while in the above works [10] to [16] it is the accumulated energy density; and b) The criterion for the prediction of the path of the mixed-mode fatigue crack propagation is 
the value of the accumulated elastic strain energy after the crack propagation, which incorporates the resulted new stress distribution due to the crack increment. In contrast in the aforementioned works of [10] to [15], the criterion for the crack path prediction is the energy density before the crack growth.

In order to verify the computation procedure shown in this work, experimental tests have been undertaken.

The main scientific contribution of this paper is the developed computation method for residual fatigue life estimation along to curve mixed-mode crack growth trajectory that is verified with own experiments.

\section{DETERMINATION OF THE CRACK GROWTH TRAJECTORY}

With the stress and strain fields around the crack-tip, fracture parameters for mixed-mode problems are calculated to predict the crack propagation path of the plate with crack. For this purpose, fracture parameters such as $K_{I}, K_{I I}$ are used. Having the fracture parameters, a criterion is needed to predict the crack growth direction in a mixed-mode problem. Several criteria have already been proposed for this purpose. Previous research [15] and [16] shows that there are no significant differences between the obtained crack trajectories based on various crack propagation criteria. Using stress as a parameter, the (MTS) criterion was presented by Erdogan and Sih [6].

This criterion states that a crack propagates in a direction corresponding to the direction of maximum tangential stress along a constant radius around the crack-tip. Using the Westergaurd stress field in the polar co-ordinates and applying the (MTS) criterion, Eq. (2) is obtained to predict the crack propagation direction in each incremental step [16].

The fracture toughness for a brittle material is usually measured in a pure mode- $I$ loading conditions, noted by $K_{I C}$. For a general mixed-mode case, we need a criterion to determine the angle of incipient propagation with respect to crack direction, and a critical combination of stress intensity factors that lead to crack propagation. Various criteria have been proposed by researchers of mixed-mode crack propagation, including the maximum energy release rate, the minimum strain energy density criteria, the maximum circumferential tensile stress, etc.

The maximum energy release rate was demonstrated by Erdogan and Sih [6] by assuming the Griffith theory as a valid criterion for crack growth. Based on this theory, the crack propagates in the direction for which the elastic energy release rate per unit crack extension becomes maximal. In this case, the crack begins to grow when the energy release reaches a critical value [6]. The minimum strain energy density theory, proposed by Sih [6], postulates that a crack propagates when the strain energy density at a critical distance reaches a minimum value. The numerical implementation of this theory can be seen in [9] to [15]. The maximum circumferential tensile stress theory was presented by Erdogan and Sih [6] based on the state of stress near the crack tip.

Based on the maximum circumferential tensile stress, the hoop stress reaches its maximum value on the plane of zero shear stress. Assuming that the size of plastic zone at the crack tip is negligible, we can use the singular term solutions of stress at the crack tip to determine the crack propagation angle, where the shear stress becomes zero. The crack propagation angle $\theta_{0}$ can be expressed by using the angle between the line of crack and the crack growth direction, with the positive value defined in the anti-clockwise direction, as:

$$
\begin{aligned}
& \Theta_{o}=2 \tan ^{-1}\left(\frac{K_{I}}{4 K_{I I}}-\frac{1}{4} \sqrt{\left(\frac{K_{I}}{K_{I I}}\right)^{2}+8}\right) \text { for } K_{I I}>0, \\
& \Theta_{o}=2 \tan ^{-1}\left(\frac{K_{I}}{4 K_{I I}}+\frac{1}{4} \sqrt{\left(\frac{K_{I}}{K_{I I}}\right)^{2}+8}\right) \text { for } K_{I I}<0 .
\end{aligned}
$$

To initiate crack propagation, the maximum circumferential tensile stress $\sigma$ must reach critical value. This results in an expression for the equivalent stress intensity factor SIF in mixed-mode condition as:

$$
K_{e q}=K_{I} \cos ^{3} \frac{\Theta_{0}}{2}-\frac{3}{2} K_{I I} \cos \frac{\Theta_{0}}{2} \sin \Theta_{0} .
$$

However, when the plastic zone size cannot be ignored, it is necessary to use the stress state at a material-dependent finite distance from the crack tip.

\section{COMPUTATION AND EXPERIMENTAL RESULTS}

In this work, two types of problems are considered: i) determination of the crack growth trajectory and ii) estimation of the residual life along the 'curve' mixed-mode crack growth trajectory.

\subsection{Crack Growth Trajectory}

To illustrate determination of the crack growth trajectory under mixed modes $I / I I$, a duraluminum plate with two holes and an initial crack under 
tension load $F_{y}$ are considered, as shown in Fig. 1. To determine stress intensity factors $K_{I}$ and $K_{I I}$, the Msc/ Nastran software code [17] is used here. In Fig. 2, the finite element model with stress distributions of the cracked specimen is shown.

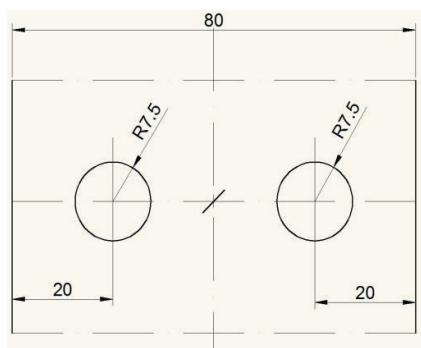

Fig. 1. Geometry of specimen for modelling of crack growth trajectory
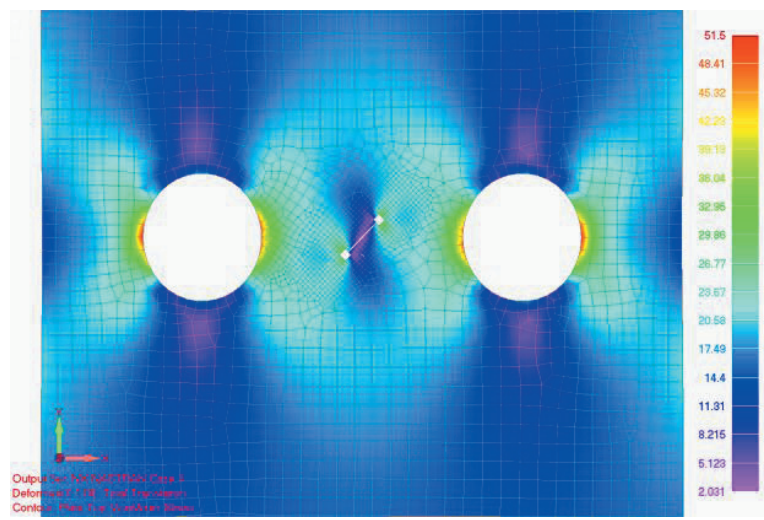

Fig. 2. Stress distributions of cracked specimen using finite elements $\left(F_{y}=60000 \mathrm{~N}\right)$

To predict the crack growth direction in a mixedmode problem, in this analysis, the MTS criterion [15] and [16] is used in combining Msc/Nastran code [17]. Combining finite elements for determination of the stress intensity factors and MTS criterion, the computation crack trajectory is obtained, Fig. 3.
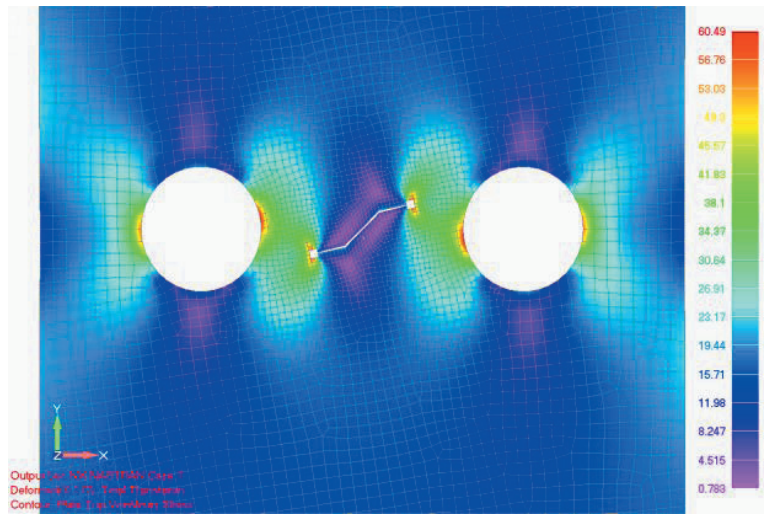

Fig. 3. Computation crack growth trajectory
To validate the computation procedure for determination of the crack growth trajectory, an experimental test is included; it was carried out using a servo-hydraulic MTS system, Figs. 4 and 5.

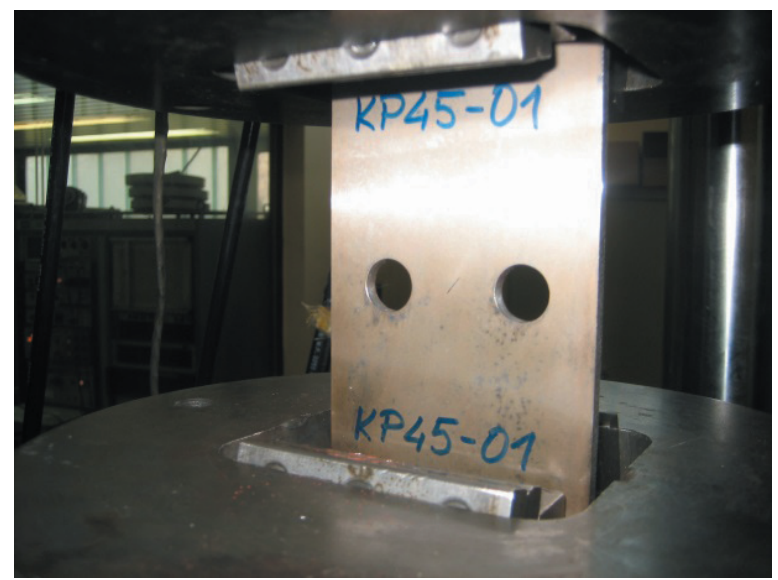

Fig. 4. Specimen in servo hydraulic MTS system

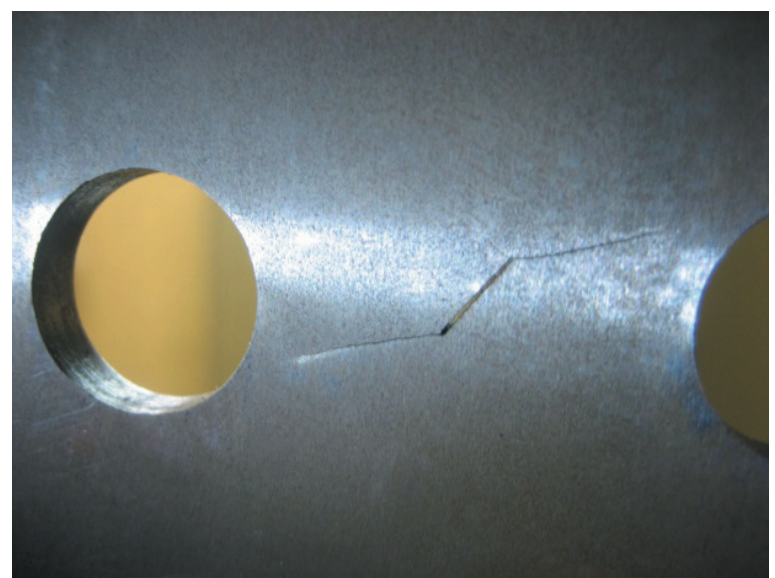

Fig. 5. Experimentally determined of crack growth trajectory

Fig. 6 illustrates good agreement between computation crack growth trajectories and those of the experiments.

\subsection{Residual Life Estimation}

Here, the residual life of cracked structural element, Fig. 6. is considered, numerically and experimentally. To determine the computation of residual life for this structural element Eq. (1) is used, along the mixedmode crack growth trajectory. For that purpose, an analytic formula for equivalent stress intensity factor $K_{e q}$ is necessary. For determination of the analytic formula of $K_{e q}$, discrete values of the stress intensity factors along the crack trajectory are used. Discrete values of SIF's are given in Table 1. 
Table 1. Discrete values of SIF's along mixed-mode crack growth trajectory

\begin{tabular}{lccccc}
\hline$a[\mathrm{~mm}]$ & $a_{0}=3$ & $a_{0}+a_{1}=7$ & $a_{0}+\ldots+a_{2}=9.5$ & $a_{0}+\ldots+a_{3}=11.5$ & $a_{0}+\ldots+a_{4}=12.9$ \\
\hline$K_{l}\left[\mathrm{daN} / \mathrm{mm}^{3 / 2}\right]$ & 37.6 & 90.8 & 123.5 & 162.5 & 177 \\
\hline$K_{l /}\left[\mathrm{daN} / \mathrm{mm}^{3 / 2}\right]$ & 21 & 9.5 & 2.2 & -1 & 2.5 \\
\hline$\theta_{i}[0]$ & 45 & 32 & 5.9 & 0.7 & 3.2 \\
\hline
\end{tabular}

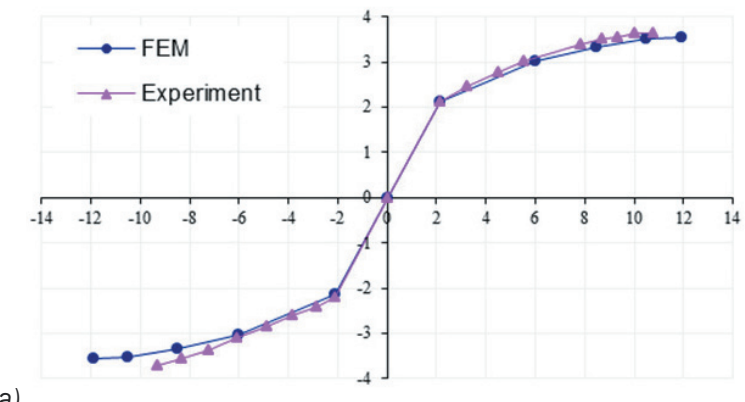

a)

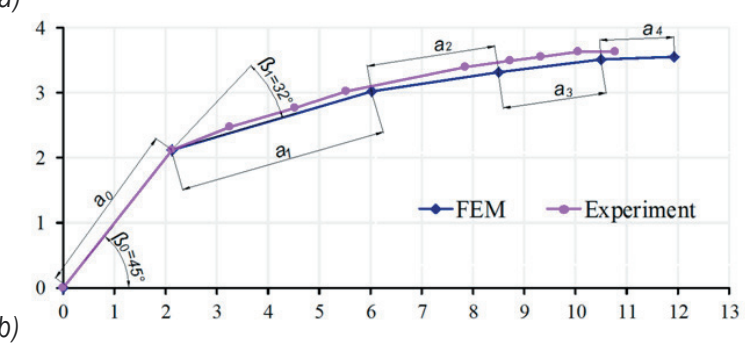

Fig. 6. Comparison computation with experimental crack growth trajectory: a) complete crack growth trajectory,

b) right part trajectories

Using discrete values of SIFs from Table 1 and the relation for equivalent SIF in the next form [21]:

$$
K_{e q}=\left[K_{I}^{4}+8 K_{I I}^{4}\right]^{1 / 4}
$$

we can obtain analytic formulae for the stress intensity factor along the crack growth trajectory, in accordance to Fig. 6, in the next form:

$K_{e q}=-2 E+07 a^{3}+820616 a^{2}-5217.1 a+20.311$,

in which a is the crack length along crack trajectory.

To determine the residual life of the cracked structural component, the analytic formula Eq. (5) has been used in Paris's law, Eq. (1). Paris's constants for considered steel (1.7225) are $C=0.00000000058$, $n=2.57$. Specimens are tested under cyclic load of constant amplitude in which $\sigma_{\max }=250 \mathrm{MPa}$ and $\sigma_{\min }$ $=25 \mathrm{MPa}$. The crack length versus number of loading cycles is shown in Fig. 6.

The experimentally determined number of cycles before failure is $N_{\text {exp }}=32200$ cycles, as shown in Fig. 7. Residual life estimation under mixed-mode crack growth is computed from point $a_{0}$ to point $a_{4}$ in accordance Fig. 6 b.

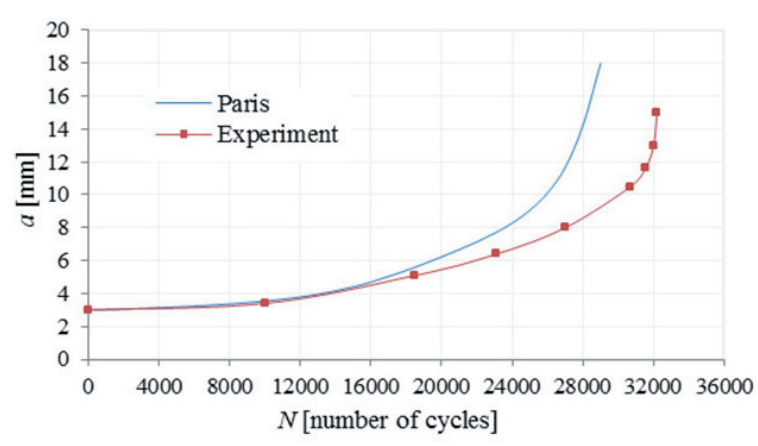

Fig.7. Comparisons computation with experimental crack growth trajectory

\section{CONCLUSIONS}

During the service of various structures, including those of aircraft, crack directions are not often normal to the loading direction. In such practical cases, the direction of crack growth is not obvious. Tests to predict the fatigue crack growth trajectory for mixedmode cracks are not only costly, but they also do not explain how each structural component in a complex structure could be optimized with another's so that the fatigue life of the overall structure can be predicted within reasonable limits for establishing the periods of inspection.

In this work, a computation procedure to predict the direction and the growth rate of a mixed mode fatigue crack, using mode-I and mode-II data from finite elements, has been attempted. Computation of the crack growth trajectory is compared with experimental results. Good agreement between computation and experimental trajectories has been obtained. The residual fatigue life along mixed mode crack growth trajectory has been determined analytically and experimentally. Good agreement between residual life estimation with experiment has also been obtained.

\section{ACKNOWLEDGMENTS}

The authors would like to thank the Ministry of Education and Science of Serbia for financial support under project number OI 174001 and TR 35045. 


\section{REFERENCES}

[1] Journet, B., Ohrloff, N., Pavlou, D., Pantelakis, S., Scra, L., Poole, D., Smart, J. (1993). Investigation on Al-Li Alloys for Damage Tolerant Applications. B/E3250 project, task 4 (Flight Simulation), Final Report DCR/M-60365/F-93, AEROSPATIALE, Suresnes.

[2] Pantelakis, S., Kermanidis, T., Pavlou, D. (1995). Fatigue crack growth retardation assessment of 2024T3 and 6061-T6 aluminum specimens. Journal of Theoretical and Applied Fracture Mechanics, vol. 22, no. 1, p. 35-42, DOI:10.1016/0167-8442(94)00046-4.

[3] Pavlou, D.G. (1998). The influence of the crack tip plastic zone strain hardening on the metal high-cyclefatigue behavior. Proceedings of the $5^{\text {th }}$ International Conference on Structures under shock and impact. Thessaloniki, Southampton: Computational Mechanics Publications, p. 633-647.

[4] Pavlou, D.G. (2000). Prediction of fatigue crack growth under real stress histories, Engineering Structures, vol. 22 , no. 12 , p. 1707-1713, DOI:10.1016/S01410296(99)00069-3.

[5] Paris, P.C., Erdogan, F. (1963). A critical analysis of crack propagation Laws. Transaction ASME, Journal of Basic Engineering, vol. 85, no. 4, p. 528-533, DOI:10.1115/1.3656900.

[6] Erdogan, F., Sih, G.C. (1963). On the crack extension in plates under plane loading and transverse shear. Transaction ASME, Journal of Basic Engineering, vol. 85, p. 519-525, DOI:10.1115/1.3656897.

[7] Gdoutos, E.E. (1984). Problems of Mixed Mode Crack Propagation. Martinus Nijhoff Publishers, Haag, p. 187-200, DOI:10.1007/978-94-009-6189-0 9.

[8] Stamenkovic, D., Maksimović, K., NikolićStanojević, V., Maksimovic. S., Stupar, S., Vasović, I. (2010). Fatigue life estimation of notched structural components. Strojniški vestnik - Journal of Mechanical Engineering, vol. 56, no. 12, p. 846-852.

[9] Maksimovic, S., Maksimovic, K. (2012). Improved computation method in residual life estimation of structural components, theoretical and applied mechanics. Special Issue of Theoretical and Applied Mechanics, vol. 40, (S1), p. 223-246, DOI:10.2298/ TAM12S1247M.

[10] Sih, G.C., Barthelemy, B.M. (1980). Mixed-mode fatigue crack growth predictions. Engineering Fracture Mechanics, vol. 13, no. 3, p. 439-451, DOI:10.1016/0013-7944(80)90076-4.

[11] Khan, S.M.A, Khraisheh, M.K. (2000). Analysis of mixed mode crack initiation angles under various loading conditions. Engineering Fracture Mechanics, vol. 67, no. 5, p. 397-419, DOI:10.1016/S00137944(00)00068-0.
[12] Blažić, M., Maksimović, K., Assoul, Y. (2011). Determination of stress intensity factors of structural elements by surface cracks. $3^{\text {th }}$ Serbian Congress Theoretical and Applied Mechanics, Vlasina Lake, p. 374-383.

[13] Theoharis, P.S., Andrianopoulos, N.P. (1982). The T-criterion applied to ductile fracture. International Journal of Fracture, vol. 20, no. 4, p. R125-R130, DOI:10.1007/BF01130617.

[14] Qian, J., Fatemy, A. (1996). Mixed mode fatigue crack growth: a literature survey. Engineering Fracture Mechanics, vol. 55, no. 6, p. 969-990, DOI:10.1016/ S0013-7944(96)0071-9.

[15] Boljanović, S., Maksimović, S. (2011). Analysis of the crack growth propagation process under mixedmode loading. Engineering Fracture Mechanics, vol. 78, no. 8, p. 1565-1576, DOI:10.1016/ j.engfracmech.2011.02.003.

[16] Shafique, Khan, S.M.A., Marwan, K.K. (2000). Analysis of mixed mode crack initiation angles under various loading conditions. Engineering Fracture Mechanics, vol. 67, no. 5, p. 397-419, DOI:10.1016/ S0013-7944(00)00068-0.

[17] Msc/NASTRAN software code- Theoretical Manuals, (1994). The MacNeal Schwendler Corporation, Los Angeles.

[18] Rusinski, E., Moczko, P., Pietrusiak, D., Przybyłek, G., (2013). Experimental and numerical studies of jaw crusher supporting structure fatigue failure. Strojniški vestnik - Journal of Mechanical Engineering, vol. 59, no. 9, p. 556-563, DOI:10.5545/sv-jme.2012.940.

[19] Pavlou, D.G., Labeas, G.N., Vlachakis, N.V., Pavlou, F.G. (2003). Fatigue crack propagation trajectories under mixed-mode cyclic loading. Engineering Structures, vol. 25, no. 7, p. 869-875, DOI:10.1016/ S0141-0296(03)00018-X.

[20] Tanata, K. (1974). Fatigue crack propagation form a crack inclined to the cyclic tensileaxis. Engineering Fracture Mechanics, vol. 6, no. 3, p. 499-507, DOI:10.1016/0013-7944(74)90007-1.

[21] Petrašinović, D., Boško, R., Petrašinovic, N. (2012). Extended finite element method (XFEM) applied to aircraft duralumin spar fatigue life estimation. Tehnički vjesnik - Technical Gazzete, vol. 19, no. 3, p. 557-562.

[22] Maksimovic, S., Vasović, I., Maksimović, M., Đurić, M., (2013). Some aspects of the damage tolerance analysis of the LASTA training aircraft structures. Scientific Technical Review, vol. 63, no. 2, p. 70-74.

[23] Jovicic, G., Živković, M., Maksimović, K., Đorđević, N. (2008). The crack growth analysis on a real structure using the X-FEM and EFG methods. Scientific Technical Review, vol. 58, no. 2, p. 21-25. 